\title{
Takotsubo Cardiomyopathy Associated with Thyrotoxicosis: A Case Report and Review of the Literature
}

\author{
Myrto Eliades, ${ }^{1}$ Diala El-Maouche, ${ }^{2}$ Chitra Choudhary, ${ }^{1}$ Bruce Zinsmeister, ${ }^{1,3}$ and Kenneth D. Burman ${ }^{1,3}$
}

Background: Takotsubo or stress-induced cardiomyopathy is a form of reversible cardiomyopathy commonly associated with emotional or physical stress. Thyrotoxicosis has been identified as a rare cause of Takotsubo cardiomyopathy, with only 12 cases reported in the literature. Here, we report a case of thyroid storm presenting with Takotsubo cardiomyopathy in the setting of Graves' disease.

Patient Findings: A 71-year-old woman presented with abdominal pain, vomiting, confusion, and history of weight loss. She was initially diagnosed and treated for diabetic ketoacidosis at another hospital and was transferred to our hospital one day after initial presentation because of concern for acute coronary syndrome. A diagnosis of Takotsubo cardiomyopathy was made on the basis of cardiac catheterization. At that time, she was diagnosed and treated for thyroid storm. Follow-up 7 weeks later revealed improvement of her cardiac function and near-normalization of thyroid hormone levels.

Summary: In this patient, who presented with symptoms of heart failure, acute coronary syndrome was initially considered, but the diagnosis of Takotsubo cardiomyopathy associated with thyroid storm was ultimately made based on cardiac catheterization and laboratory investigation.

Conclusions: Thyrotoxicosis is associated with adverse disturbances in the cardiovascular system. Takotsubo cardiomyopathy could be a presenting manifestation of thyroid storm, perhaps related to excess catecholamine levels or sensitivity.

\section{Introduction}

$\mathbf{H}$ ISTORICALLY, THE EFFECTS OF THYROID HORMONE On the cardiovascular system were first described by Robert Graves in 1835 (1). It was not until later in 1924 when Levine and Sturgis (2) introduced the concept of cardiac disease provoked by hyperthyroidism on the basis of their clinical observations of patients who presented with atrial fibrillation, tachyarrhythmias, and heart failure, masked by underlying hyperthyroidism.

Thyroid hormone has both direct and indirect actions on the cardiovascular system. Biologically active thyroid hormone, triiodothyronine (T3), increases cardiac contractility both directly by acting on cardiac myocytes and indirectly by causing peripheral vasodilatation that leads to a decrease in systemic vascular resistance and eventually to an increase in cardiac output and blood volume (3). However, in cases of thyrotoxicosis the hypervolemic burden can lead to reduction in myocardial contractile reserve and finally to heart failure.
Stress-induced cardiomyopathy, also known as Takotsubo cardiomyopathy, is a form of reversible, nonischemic cardiomyopathy reported to be triggered by stressful events. It was first described in Japan in the early 1990s (4) and has been increasingly recognized since then. It is characterized by normal coronary arteries and a distinctive left ventricular contraction pattern of apical or midventricular dyskinesis or akinesis, which explains its description as "apical ballooning syndrome" (5). The precipitants of Takotsubo cardiomyopathy are either emotional or physical stress, including acute medical illness (6). We report a case of Takotsubo cardiomyopathy in a patient with thyrotoxicosis associated with Graves' disease.

\section{Patient}

A 71-year-old woman was admitted to our institution because of abdominal pain, vomiting, and altered mental status. The patient had been well until 2 days prior to presentation

\footnotetext{
${ }^{3}$ Sections of Endocrinology and Cardiology, ${ }^{1}$ Department of Internal Medicine, Medstar Washington Hospital Center, Washington, District of Columbia.

${ }^{2}$ National Institute of Diabetes and Digestive and Kidney Diseases, National Institutes of Health, Bethesda, Maryland.
} 
when she started complaining of abdominal pain associated with nausea and vomiting; she was also noted by her family to be more confused with slurred speech. According to her son, she had been complaining of dizziness, dry mouth, sweating, palpitations, diarrhea, and a weight loss of 25 pounds $(11.34 \mathrm{~kg})$ over a period of 6 weeks before presentation. Her medical history was significant for type-2 diabetes of 15 years, as well as a remote history of colon cancer. She worked as a waitress, was separated from her husband, and lived alone. Her home medications included glargine-insulin 12 units daily, aspart-insulin 10 units with meals, and metformin $500 \mathrm{mg}$ twice daily. One day prior to admission to this hospital, she presented to the emergency department of another hospital where she was found to have diabetic ketoacidosis and was treated with insulin infusion. A computed tomography of the head without contrast at that time was unremarkable. In addition, an electrocardiogram revealed ST and T wave changes consistent with anterolateral ischemia, and the cardiac markers were found to be elevated (creatine kinase $\mathrm{MB} 26.3 \mathrm{ng} / \mathrm{mL}$, reference range 0.5-3.6; troponin $5.67 \mathrm{ng} / \mathrm{mL}$, reference range $0.0-0.045)$. The patient was transferred to our institution the same day for further evaluation and management because of concern for acute coronary syndrome.

On physical examination the patient was markedly confused and disoriented, tachycardic (heart rate $132 \mathrm{bpm}$ ), and tachypneic (respiratory rate $28 / \mathrm{min}$ ), with a blood pressure of $170 / 119 \mathrm{mmHg}$ in supine position and a body temperature of $37^{\circ} \mathrm{C}$. No pallor, jaundice, or proptosis was noted. Neck examination revealed a palpable thyroid gland weighing approximately $40 \mathrm{~g}$, with no discrete masses or nodules, and no bruit. Chest examination revealed bibasilar rales; tachycardia with normal S1 and S2 and with no murmurs, rubs, or gallops; and displacement of apical impulse leftward. She had hyperactive bowel sounds and a soft abdomen without abdominal tenderness or distention. Her skin was warm and had no edema in her extremities.

Within 30 minutes after presentation to our hospital, she underwent cardiac catheterization, which revealed normal coronary arteries and severe left ventricular dysfunction (ejection fraction $30 \%$ ) associated with apical and midcavity hypokinesis (Fig. 1), features consistent with Takotsubo cardiomyopathy (5). Laboratory work-up done within the first 1 hour after presen- tation included a serum chemistry panel showing elevated sodium (Na $153 \mathrm{mmol} / \mathrm{L}$ ) and creatinine (Cr $1.40 \mathrm{mg} / \mathrm{dL}$ ) levels, a normal anion gap, and mildly elevated transaminases (alanine aminotransferase $155 \mathrm{U} / \mathrm{L}$, aspartate aminotransferase $183 \mathrm{U} / \mathrm{L}$ ) (Table 1). Thyroid function tests were also determined and were found to be abnormal with an undetectable thyrotropin $(<0.05 \mathrm{mU} / \mathrm{L}$, reference range $0.4-4.0)$ and an elevated free thyroxine (T4; $5.3 \mathrm{ng} / \mathrm{dL}$, reference range $0.76-1.46)$ and total T3 (232 ng/dL, reference range 60-180). Antithyroperoxidase antibodies were negative, while the thyroid-stimulating immunoglobulin level was 3.4 (normal <1.3).

According to the Burch-Wartofsky criteria for thyrotoxi$\operatorname{cosis}(7)$, the patient had a score of $>45$ (delirium $=20$; nausea, vomiting $=10$; tachycardia $=20$; moderate pulmonary ede$\mathrm{ma}=10$ ), therefore making the diagnosis of thyroid storm highly likely. On the basis of this evidence, the patient was started on high-dose dexamethasone at $4 \mathrm{mg}$ (intravenously) every 8 hours, methimazole at $20 \mathrm{mg}$ every 8 hours, propranolol $40 \mathrm{mg}$ every 8 hours, and captopril $12.5 \mathrm{mg}$ twice daily. This successfully controlled her heart rate (down to 80s; Fig. 2) and lowered free T4 levels (Fig. 3); however, her mental status failed to significantly improve. Because of these persistent symptoms, a surgical evaluation was sought and further imaging of the neck with computed tomography was pursued; this showed a diffuse goiter (right thyroid lobe, $3.2 \mathrm{~cm} \times 3.2 \mathrm{~cm} \times 5.4 \mathrm{~cm}$; left thyroid lobe, $3.4 \mathrm{~cm} \times 2.7 \mathrm{~cm} \times 4.6$ $\mathrm{cm}$; isthmus thickened at $16 \mathrm{~mm}$ ) without nodules or cervical lymphadenopathy. At the same time, the patient was started on Lugol's solution at $0.25 \mathrm{~mL} /$ day for 5 days. On hospital day 6, methimazole was switched to propylthiouracil (300 mg three times daily) due to thrombocytopenia of unknown cause, which resolved shortly after switching to propylthiouracil and stopping proton-pump-inhibitor therapy simultaneously. Over the next 10 days, the patient's symptoms gradually improved and her free $\mathrm{T} 4$ reached near-normal levels (Fig. 3). Surgical intervention was deferred. A repeat echocardiogram performed 10 days after initial presentation showed improved left ventricular function with an ejection fraction of $45-50 \%$. At a follow-up visit 7 weeks after discharge from hospital, she was clinically euthyroid with improved mental status and a detectable thyrotropin $(1.40 \mathrm{mU} /$ $\mathrm{L})$, along with a near-normal free T4 $(0.63 \mathrm{ng} / \mathrm{dL})$ and a normal total T3 level (125 ng/dL).
FIG. 1. Left ventriculogram with wall motion abnormalities in the distal segments and normal wall motion in basal segments (arrows) comparable to stress-induced cardiomyopathy. (a) Diastolic phase. (b) Systolic phase.
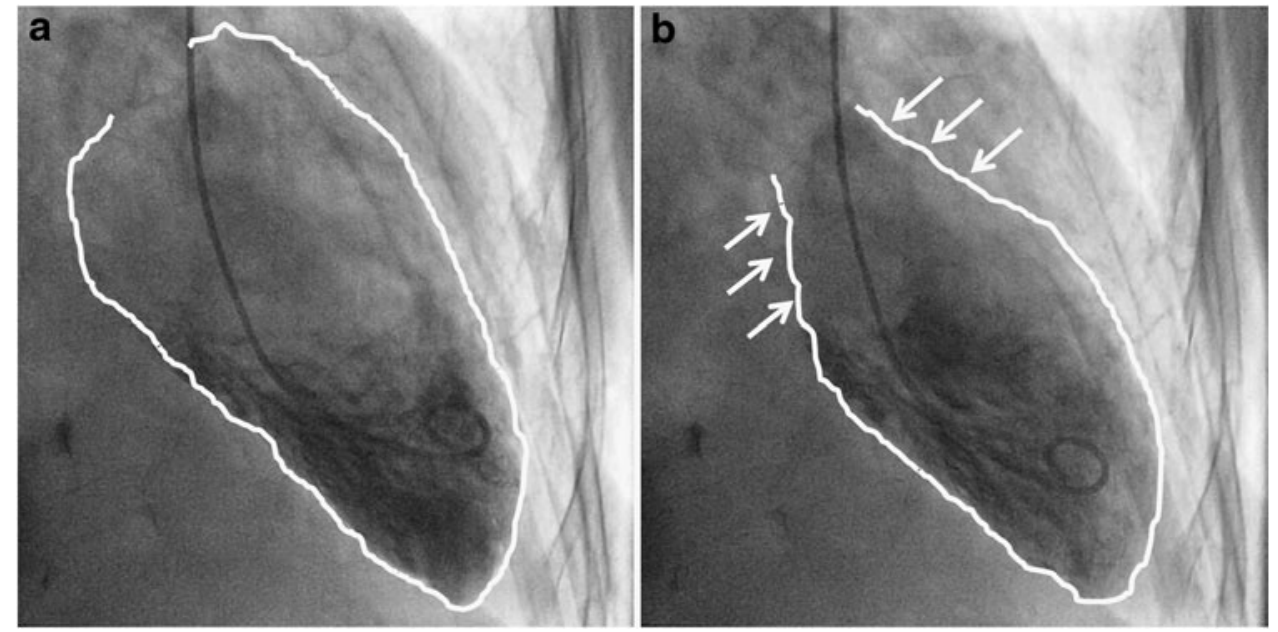


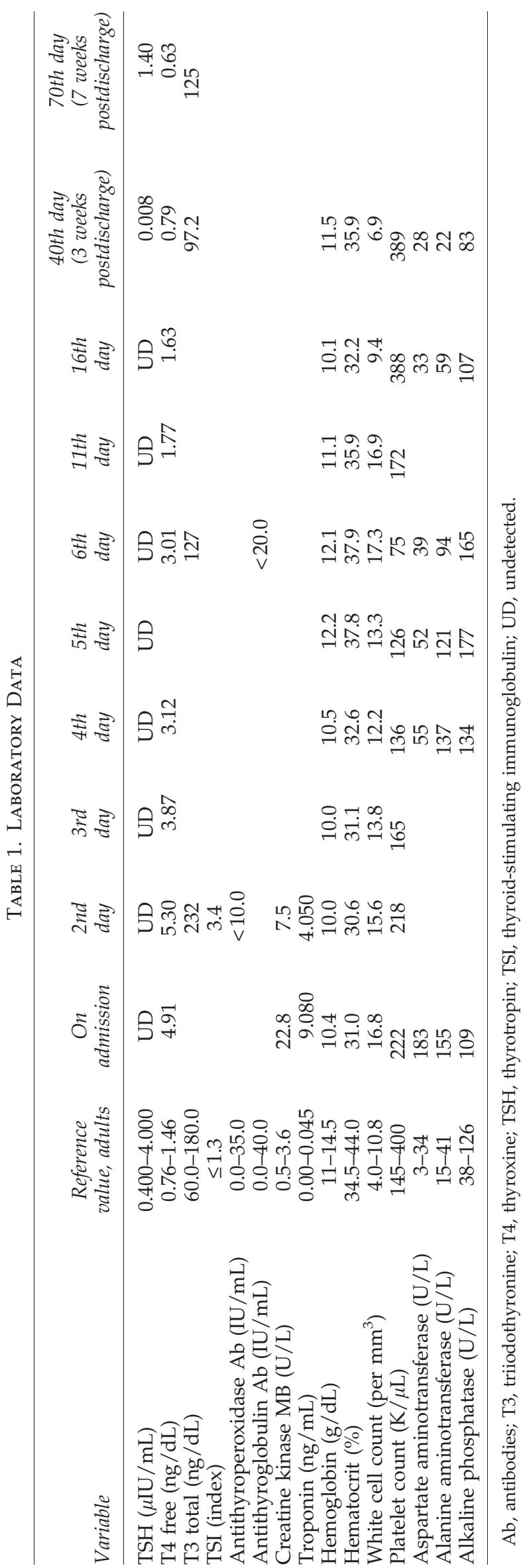

\section{Discussion}

Takotsubo cardiomyopathy is characterized by transient left ventricular dysfunction with chest symptoms, elevated cardiac enzymes, and electrocardiogram changes that resemble myocardial infarction. It is estimated that approximately $2 \%$ of patients with suspected acute ST-elevation myocardial infarction have the syndrome (5). The prevalence is higher among postmenopausal women, and attacks are usually preceded by emotional or physical stress (5). The mortality rate is, however, higher in males than in females and may be related to underlying critical illness (8). Patients have no discrete lesions in their coronary arteries, usually documented by normal coronary angiography. On ventricular angiography, the left ventricle has a characteristic morphologic appearance described as "apical ballooning" that resembles the shape of Japanese octopus fishing pots (i.e., tako tsubo; tako=octopus, $t$ subo= pot).

Several pathophysiological mechanisms have been proposed to explain the unusual features of this syndrome, including multivessel epicardial spasm, coronary microvascular impairment, and microvascular spasm (9). However, evidence supporting any of these possible mechanisms is limited and with some conflicting results. For example, multivessel epicardial spasm is only demonstrated in a small minority of these patients $(10,11)$. Currently, the most popular theory focuses on the role of endogenous catecholamines in inducing myocardial dysfunction and stunning. In fact, considerable literature supports this theory based on the findings of abnormal cardiac sympathetic innervation with sympathetic hyperactivity at the cardiac apex in patients presenting with the syndrome $(12,13)$ and the distinct marked elevation of plasma catecholamine and neuropeptide levels in these patients compared with patients with myocardial infarction (14). Case reports of Takotsubo cardiomyopathy caused by catecholamine-secreting tumors and exogenous administration of catecholamines further support the notion of catecholamine-induced myocardial stunning $(15,16)$. The precise mechanism of catecholamine-mediated myocardial stunning in Takotsubo cardiomyopathy remains unclear. A direct toxic effect on cardiac myocytes has been suggested (17). Catecholamines decrease myocyte viability through calcium overload mediated by cyclic adenosine monophosphate, resulting in contraction band necrosis, a histological pattern of myocytes injury that has been observed in Takotsubo cardiomyopathy (14) and other hyperadrenergic states (18). Data from animal models also support the hypothesis of catecholamine-mediated myocardial injury. In a rat model of Takotsubo cardiomyopathy, myocardial injury was prevented by pretreatment with combined $\alpha$ - and $\beta$-adrenoreceptor blockade (19). Similarly in monkeys, Takotsubo cardiomyopathy was induced by the infusion of intravenous epinephrine, resulting in increased myocytolysis in the apical portion of the ventricle. Administration of the beta-blocker metoprolol decreased the observed epinephrinemediated myocytolysis and resulted in improvement in left ventricular ejection fraction (20).

Inflammation might also play a role, as this has been shown in endomyocardial biopsy specimens that demonstrated focal areas with mononuclear inflammatory infiltration and fibrosis (21). In fact, a recent study suggested a significant contribution of oxidative stress to the pathogenesis of Takotsubo 
FIG. 2. Diagram of patient's heart rate (HR) in relation to treatment with beta-blockers.

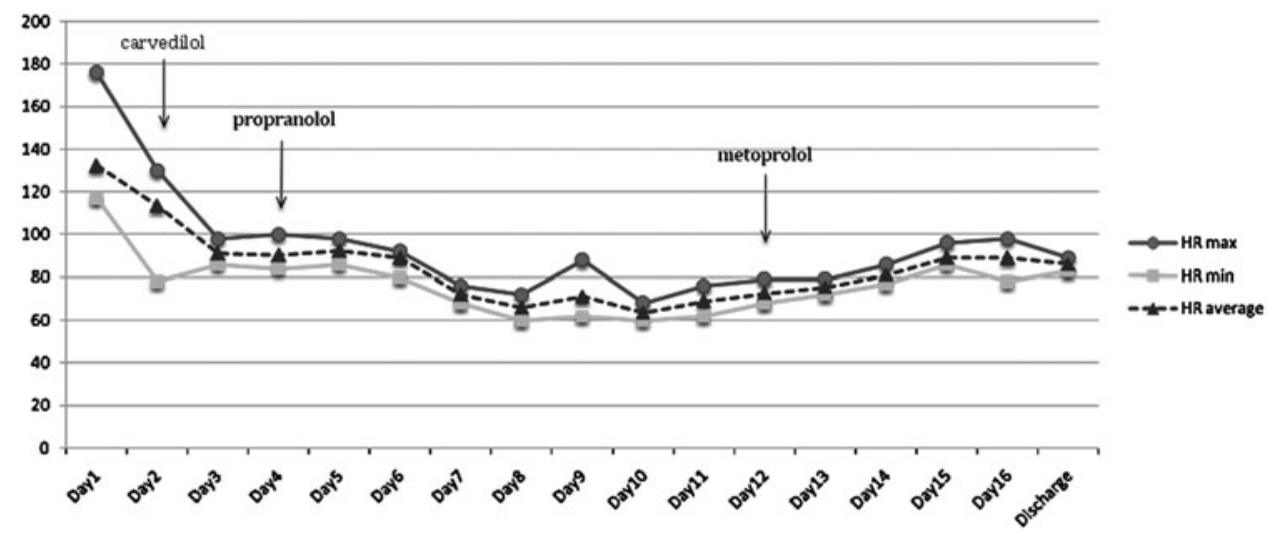

cardiomyopathy (22), which further supports the notion that regional hypokinesis of myocardium may be a sign of inflammation related to stress. Moreover, there is evidence to suggest that the release of brain natriuretic peptide (BNP) and $\mathrm{N}$-terminal pro-BNP (NT-proBNP) in these patients might be a response to inflammation; therefore, $\mathrm{BNP} / \mathrm{NT}$-proBNP may provide the basis for improved early diagnosis (23). Specifically, Nguyen et al. (24) showed that the extent of BNP and pro-BNP elevation was directly correlated with the severity of Takotsubo cardiomyopathy, as measured by the extent of normetanephrine elevation and of left ventricular systolic dysfunction, but it did not vary with pulmonary capillary wedge pressure. The authors therefore concluded that in the absence of acute pulmonary edema, a different physiologic stimulus, such as inflammation, might be the basis for this $\mathrm{BNP} / \mathrm{NT}$-proBNP release.

Finally, the cause of the strong female predisposition for Takotsubo cardiomyopathy is unknown but may be related to sex differences in myocardial sensitivity to catecholamines (25) and the potentially important role of estrogen in the pathogenesis of this syndrome (26).

Clinically, hyperthyroidism mimics a state of adrenergic excess. The thyroid and adrenergic axes are closely interrelated, and pathologically high levels of thyroid hormones cause exaggerated chronotropic and inotropic responses to catecholamines (27). This is partially mediated by the upregulation of $\beta$-adrenergic receptors by thyroid hormones in many tissues, including the heart $(28,29)$. This indirect effect of thyroid hormones on adrenergic response is validated by the observation of normal or low levels of catecholamines in patients with thyrotoxicosis $(30,31)$. Consequently, potentiation of catecholamine action by an excess of thyroid hormone has been invoked as an explanation (32).

However, the increase in $\beta$-adrenergic receptors is not always accompanied by a corresponding increase in cardiovascular sensitivity to catecholamines $(33,34)$. Experimental animal data have also shown that cardiovascular responses to hyperthyroidism are preserved in mice lacking all three $\beta$ adrenergic receptors $(\beta 1, \beta 2, \beta 3)$ compared with wild-type mice (35). Thus, an additional direct action of thyroid hormone at the intracellular level has been suggested based on the finding of thyroid hormone receptor expression on cardiac myocytes (36).

There have been several case reports of Takotsubo cardiomyopathy associated with hyperthyroidism. We identified a total of 12 cases in the literature (Table 2), most of which were associated with Graves' disease (37-42). Other causes included exogenous levothyroxine intake (43-45), Hashimoto's thyroiditis (46), and toxic multinodular goiter (47). In all cases, the patients had a complete recovery of the cardiomyopathy after treatment for thyrotoxicosis.

In our case, the patient received supportive care with betablockers and angiotensin-converting enzyme inhibitors as indicated for treatment of Takotsubo cardiomyopathy in addition to antithyroid drugs and steroids for treatment of thyrotoxicosis, resulting in full recovery and improvement of
FIG. 3. Thyroid function tests during hospital course and outpatient follow-up visits. TSH, thyrotropin; T4, thyroxine.

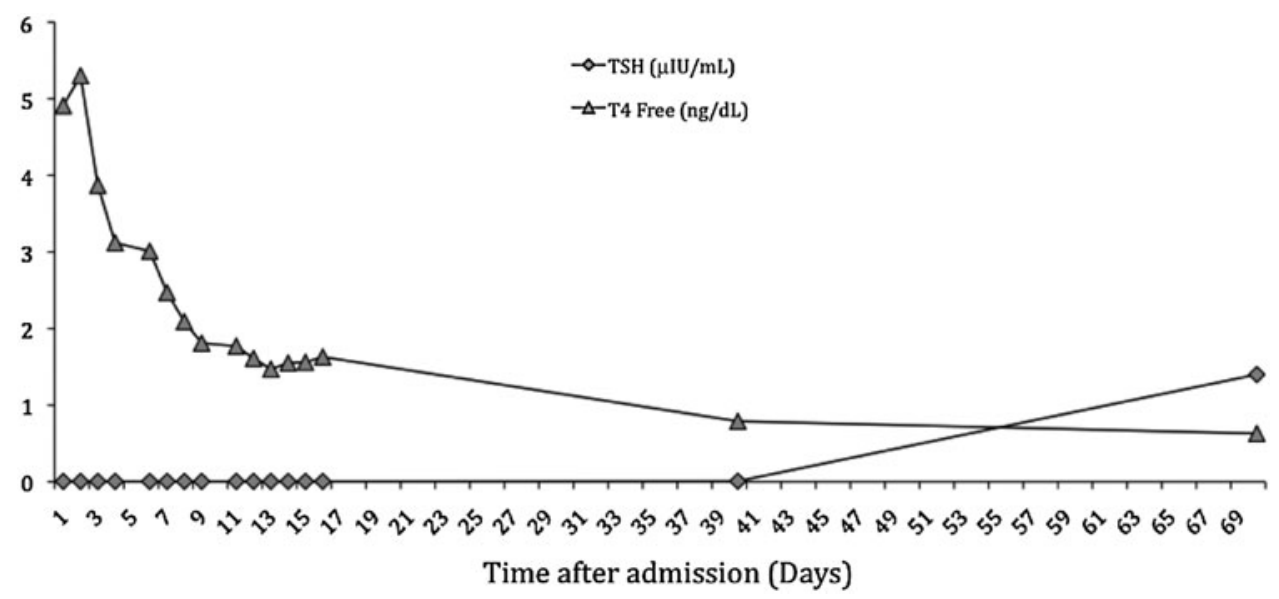




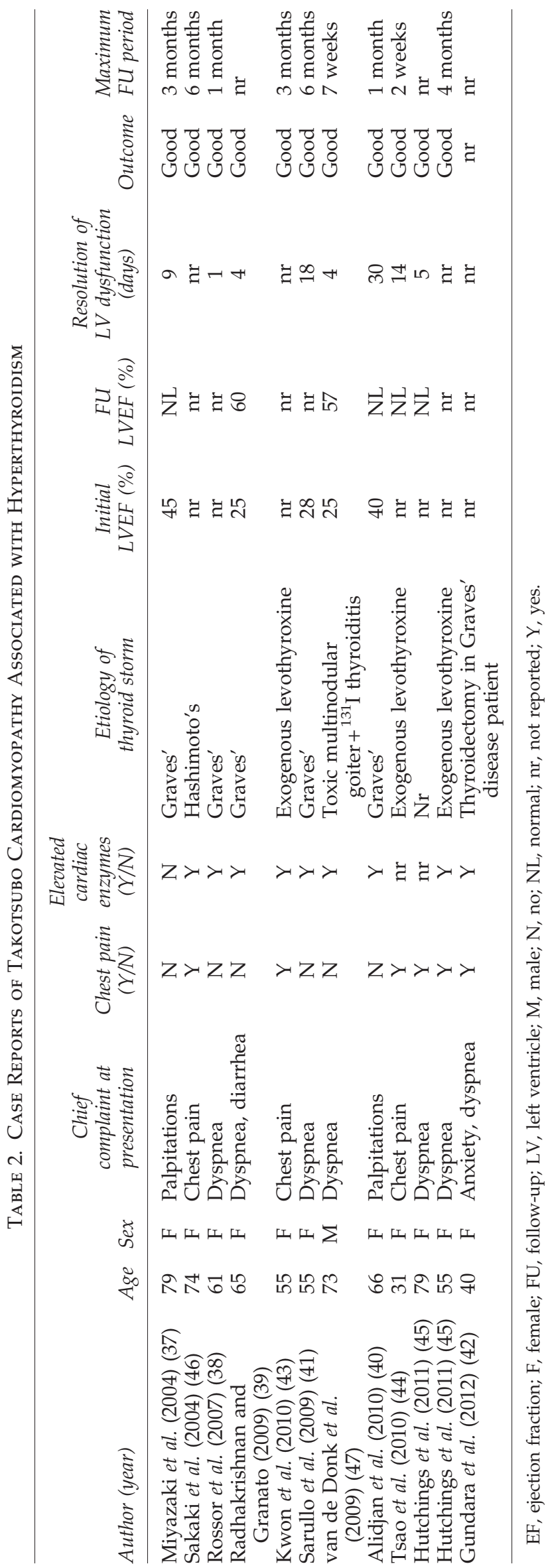

cardiac function. Whereas the ejection fraction did not restore to normal levels, it should be noted that complete recovery takes at least several months (23) and despite our efforts to obtain a repeat echocardiogram after the patient became euthyroid, the patient could not be re-evaluated.

In regard to the patient's neuropsychiatric symptoms of mental retardation and impaired cognitive function, these are well known to occur in the setting of acute thyrotoxicosis (48). Typically, there is an improvement in cognitive and behavioral impairment when patients become euthyroid, but the response can be delayed, as it was observed in our patient. In fact, one study reported that there was persistent cognitive impairment for many years after successful treatment for thyrotoxicosis (49). The explanation is not entirely clear. We know that restoration of thyroid function tests to normal may coincide with or precede amelioration of the tissue effects of hyperthyroidism. Several biomarkers, such as sex hormone-binding globulin, ferritin, and angiotensinconverting enzyme levels, have been used to indirectly assess thyroid hormone peripheral tissue sensitivity or action in hyperthyroid patients, and such measurements may have been helpful in the patient described $(50,51)$.

In conclusion, we present a case of Takotsubo cardiomyopathy in the setting of thyrotoxicosis secondary to Graves' disease. Physicians should be aware of the clinical manifestations of thyrotoxicosis and its effects on the cardiovascular system so that a reversible cause of heart failure is not missed.

\section{Author Disclosure Statement}

The authors declare that no competing financial interests exist.

\section{References}

1. Graves R 1835 Newly observed affection of the thyroid gland in females. Lond Med Surg J 7(Part 2):516-517.

2. Levine SA, Sturgis CC 1924 Hyperthyroidism masked as heart disease. Boston Med Surg J 190:233-237.

3. Klein I, Ojamaa K 2001 Thyroid hormone and the cardiovascular system. N Engl J Med 344:501-509.

4. Dote K, Sato H, Tateishi H, Uchida T, Ishihara M 1991 [Myocardial stunning due to simultaneous multivessel coronary spasms: a review of 5 cases]. J Cardiol 21:203-214.

5. Pilgrim TM, Wyss TR 2008 Takotsubo cardiomyopathy or transient left ventricular apical ballooning syndrome: a systematic review. Int J Cardiol 124:283-292.

6. Bybee KA, Prasad A 2008 Stress-related cardiomyopathy syndromes. Circulation 118:397-409.

7. Burch HB, Wartofsky L 1993 Life-threatening thyrotoxicosis. Thyroid storm. Endocrinol Metab Clin North Am 22: 263-277.

8. Brinjikji W, El-Sayed AM, Salka S 2012 In-hospital mortality among patients with takotsubo cardiomyopathy: a study of the National Inpatient Sample 2008 to 2009. Am Heart J 164:215-221.

9. Nef HM, Mollmann H, Akashi YJ, Hamm CW 2010 Mechanisms of stress (Takotsubo) cardiomyopathy. Nat Rev Cardiol 7:187-193.

10. Kurisu S, Sato H, Kawagoe T, et al 2002 Tako-tsubo-like left ventricular dysfunction with ST-segment elevation: a novel cardiac syndrome mimicking acute myocardial infarction. Am Heart J 143:448-455. 
11. Abe $\mathrm{Y}$, Kondo M, Matsuoka R, Araki M, Dohyama K, Tanio H 2003 Assessment of clinical features in transient left ventricular apical ballooning. J Am Coll Cardiol 41:737-742.

12. Akashi YJ, Nakazawa K, Sakakibara M, Miyake F, Musha H, Sasaka K 2004 123I-MIBG myocardial scintigraphy in patients with "Takotsubo" cardiomyopathy. J Nucl Med 45:1121-1127.

13. Burgdorf C, von Hof K, Schunkert H, Kurowski V 2008 Regional alterations in myocardial sympathetic innervation in patients with transient left-ventricular apical ballooning (Tako-tsubo cardiomyopathy). J Nucl Cardiol 15:65-72.

14. Wittstein IS, Thiemann DR, Lima JA, et al 2005 Neurohumoral features of myocardial stunning due to sudden emotional stress. N Engl J Med 352:539-548.

15. Scott IU, Gutterman DD 1995 Pheochromocytoma with reversible focal cardiac dysfunction. Am Heart J 130:909-911.

16. Abraham J, Mudd JO, Kapur NK, Klein K, Champion HC, Wittstein IS 2009 Stress cardiomyopathy after intravenous administration of catecholamines and beta-receptor agonists. J Am Coll Cardiol 53:1320-1325.

17. Mann DL, Kent RL, Parsons B, Cooper GT 1992 Adrenergic effects on the biology of the adult mammalian cardiocyte. Circulation 85:790-804.

18. Drislane FW, Samuels MA, Kozakewich H, Schoen FJ, Strunk RC 1987 Myocardial contraction band lesions in patients with fatal asthma: possible neurocardiologic mechanisms. Am Rev Respir Dis 135:498-501.

19. Ueyama T, Kasamatsu K, Hano T, Yamamoto K, Tsuruo $Y$, Nishio I 2002 Emotional stress induces transient left ventricular hypocontraction in the rat via activation of cardiac adrenoceptors: a possible animal model of "tako-tsubo" cardiomyopathy. Circ J 66:712-713.

20. Izumi Y, Okatani H, Shiota M, et al 2009 Effects of metoprolol on epinephrine-induced takotsubo-like left ventricular dysfunction in non-human primates. Hypertens Res 32:339-346.

21. Nef HM, Mollmann H, Kostin S, et al 2007 Tako-Tsubo cardiomyopathy: intraindividual structural analysis in the acute phase and after functional recovery. Eur Heart J 28:2456-2464.

22. Nef HM, Mollmann H, Troidl C, et al 2008 Expression profiling of cardiac genes in Tako-Tsubo cardiomyopathy: insight into a new cardiac entity. J Mol Cell Cardiol 44:395-404.

23. Neil CJ, Nguyen TH, Sverdlov AL, et al 2012 Can we make sense of takotsubo cardiomyopathy? An update on pathogenesis, diagnosis and natural history. Expert Rev Cardiovasc Ther 10:215-221.

24. Nguyen TH, Neil CJ, Sverdlov AL, et al 2011 N-terminal probrain natriuretic protein levels in takotsubo cardiomyopathy. Am J Cardiol 108:1316-1321.

25. Mori H, Ishikawa S, Kojima S, et al 1993 Increased responsiveness of left ventricular apical myocardium to adrenergic stimuli. Cardiovasc Res 27:192-198.

26. Ueyama T, Kasamatsu K, Hano T, Tsuruo Y, Ishikura F 2008 Catecholamines and estrogen are involved in the pathogenesis of emotional stress-induced acute heart attack. Ann NY Acad Sci 1148:479-485.

27. Silva JE, Bianco SD 2008 Thyroid-adrenergic interactions: physiological and clinical implications. Thyroid 18:157-165.

28. Bilezikian JP, Loeb JN 1983 The influence of hyperthyroidism and hypothyroidism on alpha- and beta-adrenergic receptor systems and adrenergic responsiveness. Endocr Rev 4:378-388.
29. Bahouth SW 1991 Thyroid hormones transcriptionally regulate the beta 1-adrenergic receptor gene in cultured ventricular myocytes. J Biol Chem 266:15863-15869.

30. Bayliss RI, Edwards OM 1971 Urinary excretion of free catecholamines in Graves' disease. J Endocrinol 49:167-173.

31. Coulombe P, Dussault JH, Walker P 1976 Plasma catecholamine concentrations in hyperthyroidism and hypothyroidism. Metabolism 25:973-979.

32. Levey GS, Klein I 1990 Catecholamine-thyroid hormone interactions and the cardiovascular manifestations of hyperthyroidism. Am J Med 88:642-646.

33. Liggett SB, Shah SD, Cryer PE 1989 Increased fat and skeletal muscle beta-adrenergic receptors but unaltered metabolic and hemodynamic sensitivity to epinephrine in vivo in experimental human thyrotoxicosis. J Clin Invest 83:803-809.

34. Crozatier B, Su JB, Corsin A, Bouanani N-H 1991 Species differences in myocardial beta-adrenergic receptor regulation in response to hyperthyroidism. Circ Res 69:1234-1243.

35. Bachman ES, Hampton TG, Dhillon H, et al 2004 The metabolic and cardiovascular effects of hyperthyroidism are largely independent of beta-adrenergic stimulation. Endocrinology 145:2767-2774.

36. Dillmann WH 2002 Cellular action of thyroid hormone on the heart. Thyroid 12:447-452.

37. Miyazaki S, Kamiishi T, Hosokawa N, et al 2004 Reversible left ventricular dysfunction "takotsubo" cardiomyopathy associated with hyperthyroidism. Jpn Heart J 45:889-894.

38. Rossor AM, Pearce SH, Adams PC 2007 Left ventricular apical ballooning (takotsubo cardiomyopathy) in thyrotoxicosis. Thyroid 17:181-182.

39. Radhakrishnan A, Granato JE 2009 An association between Takotsubo cardiomyopathy and thyroid storm. Postgrad Med 121:126-130.

40. Alidjan F, Ezzhati M, Bruggeling W, van Guldener C 2010 Takotsubo cardiomyopathy precipitated by thyrotoxicosis. Thyroid 20:1427-1428.

41. Sarullo FM, Americo L, Accardo S, et al 2009 Tako-tsubo cardiomyopathy observed in a patient with sepsis and transient hyperthyroidism. Monaldi Arch Chest Dis 72:33-36.

42. Gundara JS, Lee JC, Ip J, Sidhu S 2012 Takotsubo cardiomyopathy complicating thyroidectomy for Graves' disease. Thyroid 22:975-976.

43. Kwon SA, Yang JH, Kim MK, et al 2010 A case of Takotsubo cardiomyopathy in a patient with iatrogenic thyrotoxicosis. Int J Cardiol 145:e111-e113.

44. Tsao YT, Lin CS, Lin SH 2010 Thyrotoxicosis factitia induces Takotsubo cardiomyopathy in end-stage renal disease: a pathogenetic hypothesis. Kidney Int 77:468.

45. Hutchings DC, Adlam D, Ferreira V, Karamitsos TD, Channon KM 2011 Takotsubo cardiomyopathy in association with endogenous and exogenous thyrotoxicosis. QJM. 104:433-435.

46. Sakaki T, Fujioka Y, Akagami T, et al 2004 Cardiac wall motion abnormalities observed in a patient with transient hyperthyroidism. Jpn Heart J 45:1071-1077.

47. van de Donk NW, America YG, Zelissen PM, Hamer BJ 2009 Takotsubo cardiomyopathy following radioiodine therapy for toxic multinodular goitre. Neth J Med 67:350-352.

48. Bunevicius R, Prange AJ Jr 2006 Psychiatric manifestations of Graves' hyperthyroidism: pathophysiology and treatment options. CNS Drugs 20:897-909.

49. Perrild H, Hansen JM, Arnung K, Olsen PZ, Danielsen U 1986 Intellectual impairment after hyperthyroidism. Acta Endocrinol (Copenh) 112:185-191. 
50. Smallridge RC, Chernow B, Snyder R, Zaloga GP, Burman KD 1985 Angiotensin-converting enzyme activity. A potential marker of tissue hypothyroidism in critical illness. Arch Intern Med 145:1829-1832.

51. Smallridge RC, Rogers J, Verma PS 1983 Serum angiotensin-converting enzyme. Alterations in hyperthyroidism, hypothyroidism, and subacute thyroiditis. JAMA 250:24892493.
Address correspondence to: Myrto Eliades, $M D$

Department of Internal Medicine Medstar Washington Hospital Center

110 Irving Street NW, Suite 2A-50

Washington, DC 20010

E-mail: eliadesm@yahoo.com 